\title{
EMPOWERING THE READING READABILITY
}

\author{
Handoko
}

Email: hokondok@yahoo.com

STAI Ma'had Aly Al-Hikam Malang

Alamat Korespondensi: Arga Park Kav.4Jl. Nusa Indah Atas Malang 65141

\begin{abstract}
A general assumption about reading is that students improve their reading ability by reading a lot. This research was conducted to explain the use of extensive reading and aimed to figure out its implementation in improving students' reading readability by using the class action research technique. The data of this research relates to the students 'reading progress shown in their reading reports: spoken and written summary, reading comprehension and vocabulary mastery and their participation. The strategy was evolved in the continuity of reading. Students were encouraged to read extensively in and outside class. The findings indicated that the implementation could improve students' reading readability.This attainment demonstrated that students' reading readabilityis frosted through the continuity of reading. Other facts showed that students enjoyed reading. Students' curiosity was also a significant factor. Their high curiosity explained why students continued reading though they realized that materials they read were difficult enough. Students' self-confidence was also built as they were required to write a retelling story and to share their previous reading. Instead of their retelling and summarizing, students felt to be appreciated as readers. This appreciation indirectly helped students to improve the reading fondness.
\end{abstract}

Keywords: extensive reading, readibility.

\section{INTRODUCTION}

There is no doubt that reading habit is a daunting fact. Through a survey, United Nation Development Program stated that Indonesia is a country with low reading interest. The report concluded that in average Indonesian people read only one book in one year or even they do not read at all.

The trouble with reading not only takes place widely in the society but also infiltrates into classes of school. Fixing that situation, an effort is taken through the teaching of reading. However, reading is not as easy as opening the eyes. Reading is not interesting when it deals with content courses as it gets worse when it comes to reading in English.

Many English foreign language students have difficulty in making sense of texts they want to read. They seem to read considerably more slowly in English than in their first language, and feel less confident about reading in English. Of course, there are a number of possible reasons for this, but this is partly due to the way reading is approached in the language class (Meng, 2009). The difficulty faced by students is merely all about vocabulary; the lack of vocabulary, students' limited knowledge of English vocabulary up to deficiency of vocabulary mastery. It worsened as they still have problems with their lack understanding of reading skills, such as skimming, making inferences, finding key words, and finding main idea. This is quite disappointing since these skills are actually taught in their Junior and Senior High School.

Those students' difficulty in reading also occurs in STAI Ma'had Aly Al-Hikam Malang, where the teaching of reading is included in the intensive course program. The 
book used is Spectrum: A Communicative Course in English (Warshawky \& Byrd, 1993) that provides the practice in all four communicating skills, with a special focus on listening and reading. Thus, this programthat is intensively implemented in the language class leads students to reach only little bit of reading achievement.

This can be proven by the researchers' observation of the reading English quality of twenty students of semester three. It was found out that sixty percent had poor English vocabulary and text understanding, twenty five percent had average skills, and only fifteen percent had good vocabulary and text understanding. It showed that the students could hardly do the test consisting of reading and vocabulary questions. There were only three students who could do the test well, five students could do a half of the number of questions, and twelve students were almost unable to do the test well. The indicators were based on their competence dealing with vocabulary and reading tests in the form of final test.

To solve the students' problem above, the researcher implemented a kind of method that can help students improve their reading readability, and assists them gaining the unfamiliar words. It is done by encouraging them to read extensively through a simple reading method the-so-called Sustained Silent Reading, with an assumption that students will improve their reading readability by reading a lot (Preddy, 2005).

The course is conducted for one semester, asking the students to read a wide range of material as possible. The selection and preparation of materials are done by the students themselves. The students can read interesting reference such as websites through the personal computer with a free access provided by the school. The students are encouraged to read various materials such as short stories, magazines, novels, articles, and book chapters that match their interests and background knowledge. The purpose is to increase the students' motivation to read, as one of the 10 characteristics of successful extensive reading is determined by nature of material and interest of the students (Day \& Bamford, 1988: 7-8).
The instruction employed in this class is that in the weekly meeting, the students are required to read silently in about 30 minutes. The remaining 60 minutes are used for classroom activities like retelling the stories orally to the class, information transfer and 'read and write'. By retelling the stories, the lecturer provides the students with an opportunity to share their stories with their classmates and to practice their oral English (Meng, 2009). Considering that all of the students have sufficient time to report orally, it requires regular follow-up exercises such as story summaries or discussions (Bell, 1998).

The students' main task is reading, but writing summaries is valuable not only to provide a means for teachers to check comprehension but also to give students an opportunity to demonstrate their reading performance. In this procedure, the teacher's role is to encourage and help the students with their reading, by conferences or reader interview during or after class time, and by checking and commenting on written summaries that students do of their reading. This practice helps students improve their writing ability. (Lopez, 1989; Smith, 1988; Hedge, 1985; Susser\& Robb, 1989, in Susser and Robb, 1990).

Dealing with the vocabulary mastery, the students are required to keep a notebook to write unfamiliar words or interesting expressions they encountered in their reading. When they report what they have read, they will certainly pay attention to some key words or expressions that they might have not known before and memorize them. This is in line with an active reading, that students should be actively involved with the text by underlining and highlighting ideas, note taking key words or vocabulary, and summarizing. To reach adequate progress, this program is implemented with intervention.

\section{THEORETICAL BASIS}

As thirty minutes a week in-class reading is insufficient for the development of an adequate $\mathrm{L} 2$ reading ability, one measure which can make up for deficiencies in classroom reading opportunities is for students to engage in out-of-class reading. The course takes individually outside class 
with a reading report in written to be submitted in the following meeting. The outof-class reading has the effect of improving students' reading skills, their confidence, and self-identification as readers (Kitao, Yamamto \& Shimatani, 1990; Stoller, 1994 in,Meng, 2009).

The implementation of extensive reading program is simply action procedure in which students are engaged as active readers and reporters for what they read. Lecturer's activities are about to lead the students to read by becoming a model to follow, engage them to read actively, mediate their retelling story, collect their diaries, and ask them the feedback as reflection.

\section{METHOD}

The design of this study is classroom action research (CAR). Classroom Action Research for English learning is aimed at discovering learning-teaching strategies that match learners' styles and strategies in learning English (Latief, 2003: 99). Classroom action research design utilized in this study follows Kemmis and McTagart's cyclical process (1998). Kemmis and McTaggart (in Koshy, 2007:4) state that action research involves self-reflective spiral of planning, acting, observing and reflecting. They stated that planning involves the determination of the question that needs answering and the strategy to be used in answering it. During the acting stage, the practitioner tries out the strategy. The observation stage includes recording data on the results of the strategy and keeping a journal on practitioner's thought and reactions to the entire experience. Finally, during the reflection stage, conclusion was drawn and the original plan revised based upon the conclusion so that a new cycle can begin.

In conducting the research, the researcher was involved from the beginning to the end of the process of the research activities. The researcher posted as a teacher who conducts reading instruction using extensive reading and acted as the observer who observes carefully the whole process of English teaching and learning. The use of this design was in line with the problems which the researcher tried to solve. The researcher intended to implement the technique which could be used in reading instruction and to solve the classroom's problems appears in the process of teaching and learning.

\section{Students' reading progress}

Students' reading progress report could be traced back from the number of the materials read and the kind of materials chosen which included the number of titles and pages reached. The level of language difficulty is shown by the small number of pages they read. While, the reading level ranged from graded reader to ungraded one.

The materials to read comprised four different sources with different level of language difficulty. They are books, novels, magazines and websites. Mostly, students preferred reading books to reading three other sources. There were 23 books and a novel. Nine of sixteen students felt that the language used in those books were difficult. Only three students said that the level of language difficulty of the books were medium. One student, who read six books, asserted that one book was easy to read, two were medium, and three were difficult. While students reading three books stated that one was easy to read, two were difficult. Another student read only one book said that it was in between medium and difficult. Unlike those twelve difficult books, two other sources; novels and magazines were medium and easy to read. One student read one novel and three students prefered magazine. Another source was web. Three students felt that the languages used in websites were difficult; two others thought that it was medium, and one was easy to read. It was predicted before that internet would be an interesting reference that students preferred to read through since most of the students had personal computer with a free access to internet provided by school. However, it was found out that websites can't replace book preference.

The total materials to read were thirty two, consisting of twenty two books, one novel, three magazines, and only six websites. The number of the titles students read were 76 with the total 740 pages. Students often read those materials more than twice. On average, they reread threeto five times. This frequency of reading showed that students are challenged to read, to dig more knowledge information contained in 
books, novel, magazines, and web. One important thing to be reported here that was students' curiosity. Their high curiosity explained why they continue reading though they realized that materials they read are difficult enough.

Relating to the small number of the pages students reached, the consequence of chosen materials that were difficult to read was that students' readings were too slow. The language difficulty forced students to reread frequently. As a result, extensive reading with difficult language used hasn't shown to be effective in increasing students' reading speed. Reading speed depends on many factors. One is individual reading speed, because students can't change their original reading speed through reading a lot of materials. Another is individual reading comprehension. If students' reading comprehension is quite good, they will easily get the main point in a short time. These factors can affect students' reading speed. Therefore, extensive reading is shown not to improve students' reading speed (Bell, 2001).

The level of language difficulties was noted that 12 of 22 books were difficult and 3 of 6 web's articles were difficult, too. The total of difficult materials to read were 15, while the medium level were 11 materials consisting of 7 books, 1 novel, 2 magazines, and 2 web's articles and the easy one was only 4 taken from 2 books, 1 magazine, and 1 article in internet. This small number of easy materials indicated that when students easily finished easy reading (graded reader), they abandon it for another level; medium to difficult (ungraded reader).

\section{Students' reading report}

On students' reading report, the points represented quality that was classified into high, average, and low. The criteria used in summarizing the main ideas were that the high point (5) described the conclusion that unites the important points of the presentation and encourages future discussion. The low one (1) explained that spoken summary ends without a summary. Students' success was considered at least when their spoken summary met the criteria with the average points. The average points were on a scale of 4 to 2 . A score of 4 or 2 were in the middle. Score 4 would be somewhat clear and 2 would be somewhat evident but not entirely, while score 3 was with a criterion that the conclusion summarizes the main ideas.

During eight meetings, not all students could do spoken summary due to their absence. Students' lack of attendance reduced their participation in post reading activities. Seven students scored 2, 7 students scored 3, one got 4 and another one got 5 .

The result of spoken summary showed that no one fails in summarizing. The scores in Table 1 below showed the students' ability on how to convert a long text becomes short one. The indicator of that developed skill of summary could be seen from the number of scores where students were able to come to the conclusion that summarizes the main ideas. There were seven students reached this criterion. Compared with the written summary, the spoken summary is shorter than the written one. It was not so easy to retell longer than to rewrite. However, students were motivated to demonstrate what was read through spoken summary. The spoken summary situation was also rather dynamic than the written one.

Unlike spoken summary, students who missed the class were still required to completely summarize what they read for eight meetings. There were 128 diary sheets covering title of the book, the author and year, pages, content: summary, reasons to read, and level of language difficulty. These oral repots were done by sixteen students. For this reason, students' absences didn't influence the score they gained.

The scores on the average points were in between a scale of 4 to 2 . Seven students got 4 , four students got 3 , and five students got 2 . Those scores showed students' progress in clear understanding of texts. The written summary was clearly improved than in spoken one. This achievement justified that the written descriptions would be more precise than the spoken one.

As the purpose of writing a summary was to accurately represent what the author wanted to say, students had correctly cited anything directly quoted from the text. Firstly many students rewrote any quotations for the accuracy by copy-paste strategy and for simplification that highlights the major 
points, it seemed like they just recalled the main ideas of texts that were explicitly written as they were. These mistakes naturally happened so that students could learn that in summary only indirect speech is used and students have to write in their own language.

In their summarizing, there were two possibilities of shortening occurred. Both showed that first, students were smart enough to keep a summary short since people are always eager to read something short than somewhat long, and the longer something is, the greater a chance there is of including mistakes or misinformation within piece of writing. Second, too short summary confirmed that students were tired of writing since they were required not only to read but also to write. However, this possibility in shortening explained the reading achievement as shown in their both spoken and written summary.

Compared with written summary, oral report needed more alloted time. Written report could be done out of class while students were also required to read extensively. Another explanation of what students reported in written was that they really shortened as short as possible. They argued that they were tired of writing while they were busy in reading. However, summary was needed to demonstrate that students clearly understood the texts they read and that they could communicate that understanding to classmates.

Through the activities like retelling the stories orally to the class, information transfer and 'read and write' or summarizing, the extension of students' reading occurs as the lecturer provides the students with an opportunity to share their stories with their classmates and to practice their oral English (Meng, 2009). In line with this, Bell (1998) asserted that in considering that all of students have sufficient time to report orally, it requires regular follow-up exercises such as story summaries or discussions.Students' discussion and sharing with their lecturer or classmates is an effective and pleasurable way for them to learn to read in English.
Allowing students to read material they are interested in and asking them to share their opinions after reading enforce greater student motivation in reading English materials. These arise the opportunity for teachers to ask students to read more difficult articles or materials which basically are not interesting to students. It presents a more positive learning environment to both teachers and students of English as a foreign language environments.

\section{Students' reading comprehension}

The reading comprehension test evaluated how well students understood the texts. The test was intended for only one topic taken from various different sources of students' reading. The questions were focused on students' comprehension of the global information from the text they read and how clear they found the main points of the text.

The test result would be an evidence of students' reading achievement. Students' score proved their successful reading. This test confirmed the truth of students 'reading report that were in both written and spoken summary. The result showed that only one student with a score that meet the lowest minimum limit of criteria of success. It means that all of the students were able to comprehend the texts. This attainment pointed that students' reading comprehension was developed through the continuity of active reading inside and outside class. Students can acquire a more extensive vocabulary, build their reading ability, and access to background information through extensive reading.

The result of reading comprehension test indicates that if students read more, their vocabulary recognition will be developed. Once the students' ability in vocabulary has been built-up, it will become easier for them to get the main idea from articles and other texts. For this reason, students think that extensive reading can improve their reading comprehension (Shang, et al. nd). 
Table 1. Students' reading comprehension score

\begin{tabular}{|c|c|c|c|c|c|c|c|c|c|c|c|c|}
\hline \multirow[b]{2}{*}{ No } & \multirow[b]{2}{*}{$\begin{array}{l}\text { Students' } \\
\text { initials }\end{array}$} & \multicolumn{10}{|c|}{ Category } & \multirow[b]{2}{*}{ Score } \\
\hline & & $\begin{array}{l}A+ \\
100- \\
91\end{array}$ & $\begin{array}{l}\mathrm{A} \\
90- \\
86\end{array}$ & $\begin{array}{l}-A \\
85- \\
81\end{array}$ & $\begin{array}{l}B+ \\
80- \\
76\end{array}$ & $\begin{array}{l}B \\
75- \\
71\end{array}$ & $\begin{array}{l}-B \\
70- \\
66\end{array}$ & $\begin{array}{l}\mathrm{C}+ \\
65- \\
61\end{array}$ & $\begin{array}{l}\mathrm{C} \\
60- \\
56\end{array}$ & $\begin{array}{l}-C \\
55- \\
51\end{array}$ & $\begin{array}{l}\mathrm{D} \\
<50\end{array}$ & \\
\hline 1 & $\mathrm{ZA}$ & & & & & $\sqrt{ }$ & & & & & & 75 \\
\hline 2 & $\mathrm{ABM}$ & & & & $\sqrt{ }$ & & & & & & & 80 \\
\hline 3 & AS & & & & & & & $\sqrt{ }$ & & & & 65 \\
\hline 4 & MS & & & & & & & $\sqrt{ }$ & & & & 65 \\
\hline 5 & MKM & & & & $\sqrt{ }$ & & & & & & & 80 \\
\hline 6 & $\mathrm{LH}$ & & & & & & & & $\sqrt{ }$ & & & 60 \\
\hline 7 & $\mathrm{AFH}$ & & & & & $\sqrt{ }$ & & & & & & 73 \\
\hline 8 & $\mathrm{BZ}$ & & & & & & $\sqrt{ }$ & & & & & 70 \\
\hline 9 & FA & & & & $\sqrt{ }$ & & & & & & & 76 \\
\hline 10 & MH & & & & & $\sqrt{ }$ & & & & & & 71 \\
\hline 11 & MAM & & & $\sqrt{ }$ & & & & & & & & 83 \\
\hline 12 & MZS & & & $\sqrt{ }$ & & & & & & & & 82 \\
\hline 13 & $\mathrm{R}$ & & & & $\sqrt{ }$ & & & & & & & 76 \\
\hline 14 & SW & & & & $\sqrt{ }$ & & & & & & & 80 \\
\hline 15 & GSM & & & & & $\sqrt{ }$ & & & & & & 75 \\
\hline 16 & MAY & & & & & & & $\sqrt{ }$ & & & & 65 \\
\hline
\end{tabular}

\section{Students' vocabulary acquisition}

The number of unfamiliar or new words students collected during their independent reading was various ranged from 23 to 268 which is related to the level of language difficulty. There were 1386 words which justified that the more students collect the unfamiliar words the more they will get their chances to enrich their vocabularies.

To know how high they acquired the new words, students' vocabulary acquisition were tested. The test was conducted in written and spoken. For the written test, test taken from the selected new words students found in one title of their readings. The result as seen in Table 2 showed that students acquire 89.9 percent of new words they collected. The total of vocabulary gains was 708 of 787 words. The high score was 100 attained by five students and only two students with scores that were close to the minimum limit of criteria of success.

Compared with the spoken test where all students' new words collections were tested, the result showed the decline of vocabulary acquisition to 13.2 percent. A total of word gains were 1064 of 1386 words equal with 76.7 percent. This declination of vocabulary acquisition made sense due to the different total number of words being tested and different situation of both spoken and written test. For students, spoken test was more difficult than written one since they were required to memorize all the words they collected and forced to answer spontaneously. This did not happen in written test where students were more relax to answer as they got enough time to think and gave the best answer. However, the accuracy of students' vocabulary acquisition was measured through two different ways. The final scores students got were that the accumulation score of written test and spoken one divided by two. The result showed that the lowest score is 69 and the highest one is 97.8.

Table 2. Students' vocabulary acquisition

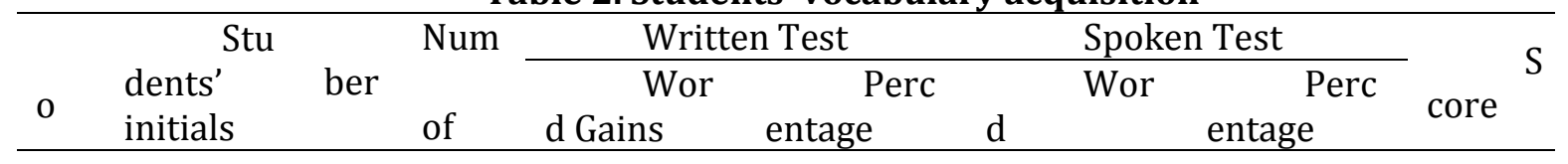




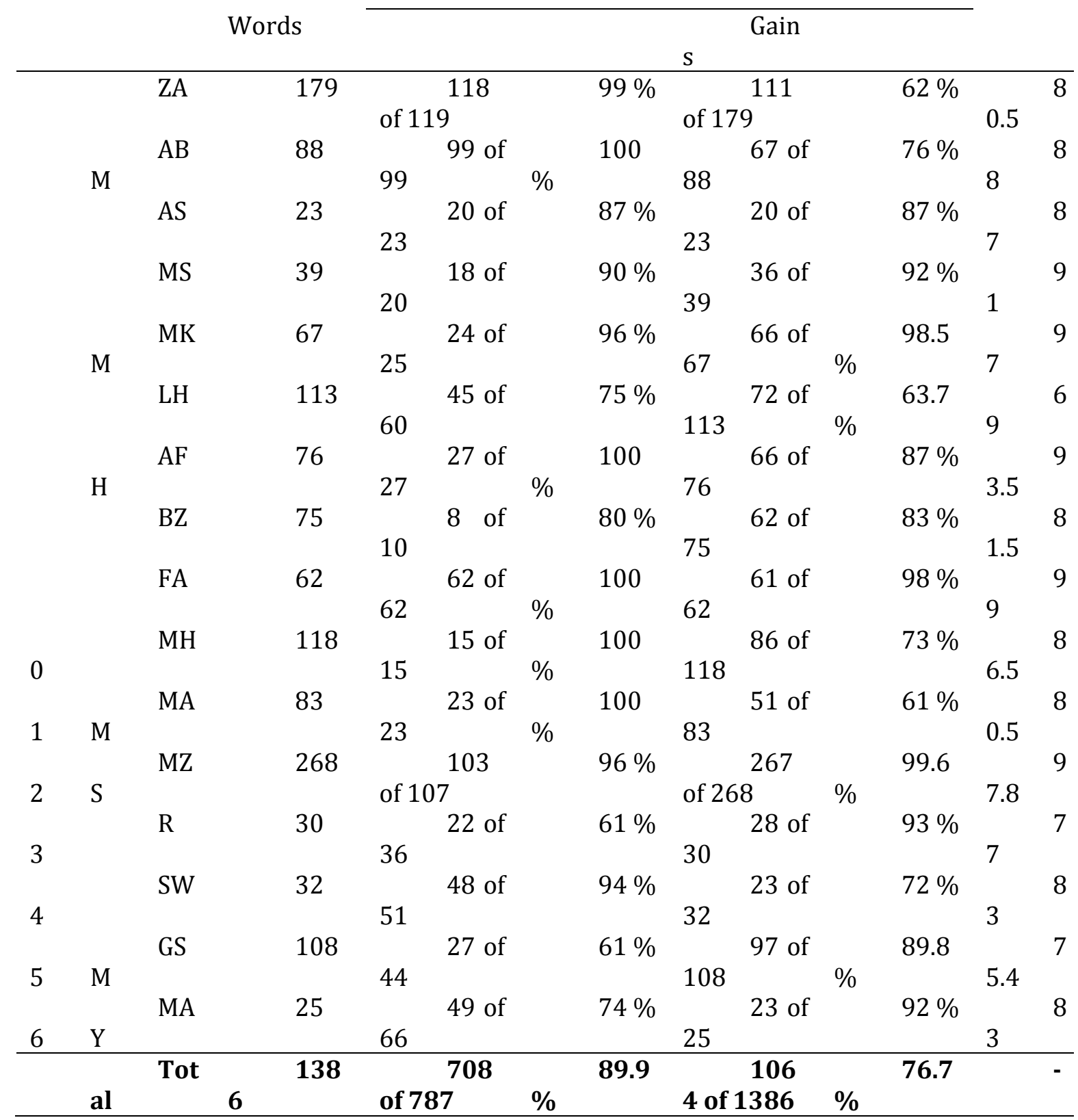

Another way to recall students' memory was that students were asked to trace back the unfamiliar words by writing them completely in their sentences, detailed with what page students read, also publisher and author. This way was aimed to confirm partially students' vocabulary acquisition. The task was taken only on one selected reading material as its vocabulary was written tested.

In the process of extensive reading, students can read some words which show up frequently in the article. When students read more and more, they will become increasingly familiar with the words to which they are frequently exposed; students' vocabulary recognition will be developed in such a process. They can acquire these words and memorize them more easily. In addition, students have greater motivation to learn some special or interesting words through reading. Consequently, extensive reading can enhance students' vocabulary (Shang, et al.nd). According to several research studies, the effects of Sustained Silent Reading on students' reading include improvement in reading skills and vocabulary acquisition, as measured by reading test scores, developing a positive attitude towards reading and cultivating a better reading habit (Preddy, 2005). 


\section{Students' shift in attitude}

There was also shift in attitude that serious negative attitude towards reading such as students shy away from reading aloud changed into confident to read silently. Students' self-confidence was built as they were required to write a retelling story and to share their previous reading. Instead of their retelling and summarizing, students were appreciated to be as readers for what they read. This appreciation indirectly helps students to improve the reading like.

Students' attitude towards reading was expressed in positive sight on reading. Reading was not like somewhat threatening anymore. Students might beat that stigmatization of reading since they could enjoy the new way of the teaching of reading.

\section{Students' participation}

Students' participation is shown not only by their attendances but also engagement in reading activity, and participation in post reading activity. Only three students were completely attending at class for fourteen meetings and one student was missing class once. Most of student skipped class for various reasons. Most frequently because the need to complete other course work, find the class boring, are ill, or have social obligation. This number of students' absence led to an assumption that most students knew well how often they were allowed to skip class since the maximum absence that offered by school was three times.

Students' attendance report also recorded the punctuality that was not on average, students didnot arrive on time. Most of students came late. They took five minutes to fifteen minutes to arrive to their class. The shocking truth was that delayed arrival due to the lodging house in where students stay, was inside school area. Students felt that they were already in school even though they were not in class.

For those students' problems in attendance and punctuality at class meeting, the treatment given was in such explanation of how important attendance on time in students' success in class. This was also motivating students about the clear benefit of attendance. However, there were always reasons for skipping class and what school can do was just ruling the maximum limit for absence. Therefore, to make up for the lack of attendances, students were required to fulfill reading report; written summary for meetings they missed.

\section{CONCLUSIONS}

The extensive reading program through sustained silent reading reported here concludes that it is a suitable and pleasurable way for undergraduates to learn to read English as a foreign language as an alternative to intensive reading courses. One important thing to be considered to reach this conclusion is that the interests of students served as control of the reading activity is left in their hands.

The strategy is evolved in the continuity of reading. Students are encouraged to read extensively in and outside class. The reading class is conducted in such way that requires the students to follow up their reading by reading report in the form of retelling story or summarizing. For these procedures, students are stimulated to read actively the materials they choose even though they are also guided to read the simplified texts or graded readers.

The findings indicate that the implementation of extensive reading program can improve students' reading readability. This attainment demonstrates that students' reading ability is developed through the continuity of extensive reading inside and outside class. Students' reading comprehension that was measured through the test shows that only one student with a score that meets the lowest minimum limit of criteria of success. This means that all of students are able to comprehend the books they read.

Even though the results of this research did not confirm the gains in reading speed and many of them didn't continue reading in English after the program finished, the fact that students enjoyed reading can be seen as very positive. All students admit in their diary: reading logs that the material was interesting, challenging and even the reluctant students valuated the books they read positively. Students' curiosity is a significant factor. Their high curiosity clarifies why students continue reading 
though they realize that materials they read are difficult enough. Students' selfconfidence is also built as they are required to write a retelling story and to share their previous reading. Instead of their retelling and summarizing, students are appreciated to be as readers for what they read. This appreciation indirectly helps students to improve the reading like. The evidence can be seen from the reluctant students who valuate the books they read positively. This explains the shift in students' attitude. Students' attitude towards reading is expressed in positive sight on reading since they could enjoy the independent reading followed by sharing or retelling, and summarizing.

In conclusion, this implementation of extensive reading program has a paramount potency to lead them to cultivate a better reading habitif students are given the opportunity and encouragement to read, allowed to select their own reading materials and conducted as a long term project that needs more than fouror fivemonths to make the students hook on books.

\section{REFFERENCES}

Bell, Timothy. 1998. Extensive Reading: Why? and How? The Internet TESL Journal,IV (12), (Online), (http://iteslj.org), accessed in January 1, 2010.

Bell, Timothy. 2001. Extensive reading: Speed and comprehension. The Reading Matrix, Vol.1. No.1, (Online), (http://www.readingmatrix.com/articles/bell/index.html), accessed in November 1, 2011.

Day, R. and J. Bamford. 1988. Extensive Reading in the Second Language Classroom. Cambridge: Cambridge University Press.

Kemmis, S and Taggart, R. 1988. The Action Research Planner. Gee. Long: Vic Deakin University Press.

Koshy, V. 2007.Action Research for Improving Practice. A Practical Guide. London: SAGE.

Latief, M. A. 2003. PenelitianTindakanKelasPembelajaranBahasaInggris. JurnalIlmuPendidikan, 10 (2). UM Malang.

Meng, Fanshao. 2009. Developing Students' Reading Ability through Extensive Reading. English Language Teaching. 2 (2), (Online), (http://www.ccsnet.org/html.journal), accessed in June 13, 2011.

Preddy, Leslie B. 2005. Sustained Silent Reading with Intervention Project, (Online), (http://www.lesliepreddy.com/SSR.html), accessed in August 11, 2011.

Shang, Hui-fang, Briody, Paul \&Lin, Chia-yun. The Effect of Extensive Reading Strategies on EFL Students, (Online), (http://spaces.isu.edu.tw/upload/18518/9602/RESEACHPAPER/ qualitativepaper4.pdf), accessed in June 14, 2011.

Susser, Bernard \& Robb, Thomas N.1990.EFL Extensive Reading Instruction: Research and Procedure. JALT Journal,12 (2), (Online), (http://www.cc.kyoto-u.ac.jp/../sussrobb.html), accessed in April 8, 2010.

Warshawky, Diane \& Byrd, Donald R. H. 1993.Spectrum: A Communicative Course in English. New Jersey: Prentice Hall. 